\title{
PARTIAL PURIFICATION AND CHARACTERIZATION OF A SUPEROXIDE DISTIMUTASE (SOD1) FROM BLACK TIGER SHRIMPS Penaeus monodon
}

\author{
Tran Minh Hien ${ }^{1}$, Nguyen Thi Hong Loan ${ }^{1,2}$, Trinh Dinh Quynh ${ }^{1}$, \\ Ngo Thi Trang ${ }^{2}$, Dang Thi Lua ${ }^{3}$, Phan Tuan Nghia, ${ }^{1,2, *}$ \\ ${ }^{1}$ Key Laboratory of Protein and Enzyme Technology, VNU University of Science, Vietnam \\ National University, Hanoi \\ ${ }^{2}$ Faculty of Biology, VNU University of Science, Vietnam National University, Hanoi \\ ${ }^{3}$ Research Institute for Aquaculture No. 1 \\ Received 26 December 2019, accepted 9 March 2020
}

\begin{abstract}
Superroxide dismutase (SOD, EC.1.15.1.1) is the enzyme which dismutates superoxide radicals and plays an important role in protection of living cells against oxidative stress. SOD is also involved in immune response in shrimps. In this study, it was found that the total SOD activity of black tiger shrimp muscular tissues is 10 fold higher than that of the haemolymph, however, the specific activity of SOD in the shrimp haemolymph is 9.2 fold higher than that of muscular tissues. By using active gel electrophoresis, 2 different SOD forms were found in black tiger shrimps (one in muscular tissues and two in haemolymph).

Using DE-52 cellulose and Q-Sepharose ion exchange column chromatography, one SOD (SOD1) from black tiger shrimp haemolymph was partially purified, and its purity was 31.2 times higher than that of the starting haemolymph. The SOD1 was shown to have mainly one protein band of approximately $24 \mathrm{kDa}$ on SDS-PAGE. SOD1 was most active at $45^{\circ} \mathrm{C}$ and $\mathrm{pH}$ of 5.5. At a concentration of $5 \mathrm{mM}, \mathrm{Mn}^{2+}$ strongly activated SOD1 (up 200\% activity), $\mathrm{Ca}^{2+}$ và $\mathrm{Zn}^{2+}$ could increase approximately $20 \%$ activity while $\mathrm{Cu}^{2+}$ inhibited more than $60 \%$ ativity of the enzyme.
\end{abstract}

Keywords: (Penaeus monodon) black tiger shrimps, ion exchange chromatography, purification, superoxide dismutase.

Citation: Tran Minh Hien, Nguyen Thi Hong Loan, Trinh Dinh Quynh, Ngo Thi Trang, Dang Thi Lua, Phan Tuan Nghia, 2020. Partial purification and characterization of a superoxide distimutase (SOD1) from black tiger shrimps Penaeus monodon. Tap chi Sinh hoc, 42(1): 93-101. https://doi.org/10.15625/0866-7160/v42n1.14737.

*Corresponding author email: phantuannghia@vnu.edu.vn

(O2020 Vietnam Academy of Science and Technology (VAST) 


\title{
TINH SẠCH MộT PHÀN VÀ NGHIÊN CÚU MộT SỐ TÍNH CHẤT CỦA SUPEROXIDE DISMUATASE (SOD1) TỪ TÔM SÚ (Penaeus monodon)
}

\author{
Trần Minh Hiền ${ }^{1}$, Nguyễn Thị Hồng Loan ${ }^{1,2}$, Trịnh Đình Quỳnh ${ }^{1}$, \\ Ngô Thị Trang ${ }^{2}$, Đặng Thị Lụa ${ }^{3}$, Phan Tuấn Nghĩa,2,"* \\ ${ }^{1}$ Phòng Thí nghiệm trọng điểm Công nghệ Enzym và Protein, Trường Đại học Khoa học Tự \\ nhiên, Đại học Quốc gia Hà Nội \\ ${ }^{2}$ Khoa Sinh học, Trường Đại học Khoa học Tự nhiên, Đại học Quốc gia Hà Nội \\ ${ }^{3}$ Viện Nghiền cứu Nuôi trồng Thủy sản I \\ Ngày nhận bài 26-12-2019, ngày chấp nhận 9-3-2020
}

\section{TÓM TẮT}

Superoxide dismutase (SOD, EC.1.15.1.1) là enzyme phân hủy gốc superoxide, thuộc nhóm các dạng oxi phản ứng và có vai trò quan trọng trong bảo vệ tổn thương oxi hóa ở các cơ thể sinh vật, đặc biệt, SOD còn có vai trò trong đáp ứng miễn dịch ở tôm. Trong nghiên cứu này, chúng tôi đã phát hiện thấy hoạt độ SOD tổng số của mô cơ tôm sú cao hơn 10 lần so với của huyết tương, tuy nhiên hoạt độ riêng SOD trong huyết tương lại cao hơn trong cơ gấp 9,2 lần so với trong mô cơ, điều này chứng tỏ có sự tập trung của SOD trong huyết tương. Bằng phương pháp điện di gel hoạt tính, chúng tôi phát hiện thấy có 2 dạng SOD trong huyết tương trong khi chỉ có một dạng SOD trong mô cơ của tôm sú.

Sử dụng phương pháp sắc ký trao đổi ion qua cột DE-52 cellulose và Q-sepharose, chúng tôi đã thu nhận được một chế phẩm SOD (SOD1) có độ sạch cao hơn ban đầu 31,2 lần; trên điện di gel polyacrylamide có chứa SDS, chế phẩm cho một băng protein chính có khối lượng phân tử khoảng $24 \mathrm{kDa}$. SOD1 hoạt động tốt nhất ở $45^{\circ} \mathrm{C}$ và $\mathrm{pH} 5,5$. Ở nồng độ $5 \mathrm{mM}, \mathrm{Mn}^{2+}$ có tác dụng hoạt hóa mạnh SOD1 (tăng lên tới $200 \%$ ), $\mathrm{Ca}^{2+}$ và $\mathrm{Zn}^{2+}$ có khả năng làm tăng $20 \%$ hoạt độ enzyme, trong khi đó $\mathrm{Cu}^{2+}$ lại ức chế hơn $60 \%$ hoạt độ của SOD1.

Từ khoá: Sắc ký trao đổi ion, superoxide dismutase, tinh sạch, tôm sú.

*Địa chỉ liên hệ email: phantuannghia@vnu.edu.vn

\section{MỞ ĐẦU}

Superoxide dismutase

(SOD, EC.1.15.1.1) là một enzyme xúc tác phản ứng chuyển hóa gốc $\mathrm{O}_{2} \cdot{ }^{-}$thành $\mathrm{H}_{2} \mathrm{O}_{2}$ và có chức năng cân bằng nồng độ các dạng oxi phản ứng và bảo vệ tế bào khỏi các stress oxi hóa (Fridovich, 1975).

Trong các loài giáp xác nói chung, nhiều đồng dạng (isoform) của SOD đã được phát hiện, các SOD này được chia thành 2 nhóm dựa vào bản chất của cofactor kim loại. Nhóm thứ nhất được ký hiệu là $\mathrm{Cu}, \mathrm{ZnSOD}$, cấu trúc từ 2 tiểu đơn vị giống nhau, với khối lượng phân tử (KLPT) khoảng $16 \mathrm{kDa}$, chứa một nguyên tử $\mathrm{Cu}^{2+}$ và một nguyên tử $\mathrm{Zn}^{2+}$ trong trung tâm hoạt động, thường định khu trong tế bào chất. Đây là dạng SOD phổ biến nhất trong các tế bào nhân thực và có trình tự axit amin bảo thủ từ các loài nấm cho đến động vật có vú (Brouwer et al., 2003). Cơ chế hoạt động của enzyme này dựa trên tính khử và oxi hóa của nguyên tử $\mathrm{Cu}^{2+}$ trong trung tâm hoạt động khi liên kết với gốc $\mathrm{O}_{2}{ }^{-}$, do đó $\mathrm{Cu}^{2+}$ không thể bị thay thế bởi kim loại khác và $\mathrm{Cu}^{2+}$ có khả năng hồi tính enzyme, trong khi 
$\mathrm{Zn}^{2+}$ có thể được thay thế bởi một vài ion kim loại khác như $\mathrm{Co}^{2+}, \mathrm{Hg}^{2+}$ hay $\mathrm{Cd}^{2+}$ mà không ảnh hưởng tới hoạt tính enzyme. $\mathrm{Cu}, \mathrm{ZnSOD}$ bị ức chế thuận nghịch bởi cyanide. $\mathrm{H}_{2} \mathrm{O}_{2}$ ở nồng độ từ $0,01 \mathrm{mM}$ có khả năng khử nguyên tử $\mathrm{Cu}^{2+}$ ở trung tâm hoạt động dẫn đến sự ức chế hoạt tính enzyme, đồng thời cũng có khả năng phá hủy cấu trúc enzyme dẫn đến sự mất hoạt tính hoàn toàn (Fridovich, 1975). Đây là một tính chất thú vi của $\mathrm{SOD}$ khi $\mathrm{H}_{2} \mathrm{O}_{2}$ là một sản phẩm trong phản ứng do nó xúc tác. Có lẽ do đó, $\mathrm{Cu}$ và $\mathrm{ZnSOD}$ thường chỉ định khu trong tế bào chất, nơi nồng độ $\mathrm{H}_{2} \mathrm{O}_{2}$ luôn được khống chế ở mức rất thấp bởi nhiều enzyme khác như catalase, peroxidase,... (Hodgson \& Fridovich 1975). Nhóm SOD thứ hai có chứa $\mathrm{Mn}^{2+}$ trong trung tâm hoạt động, ký hiệu MnSOD, thường định khu trong ty thể. Enzyme này có dạng homodimer, cấu thành từ hai tiểu đơn vị giống nhau có KLPT vào khoảng 24-25 kDa. MnSOD được phiên mã và dịch mã từ gen nhân thành dạng tiền chất, sau đó được di chuyển từ tế bào chất vào ty thể sau khi được loại bỏ một đoạn peptide định hướng ở đầu N (Brouwer et al., 2003).

Nhiều nghiên cứu đã cho thấy MnSOD có nguồn gốc hoàn toàn khác so với $\mathrm{Cu}, \mathrm{ZnSOD}$, mặc dù cơ chế hoạt động của 2 enzyme này là tương tự nhau. MnSOD ở các sinh vật nhân thực có sự tương đồng cao với MnSOD của các loài vi khuẩn, gợi ý rằng chúng có nguồn gốc rất gần gũi (Fridovich, 1975). Giống với $\mathrm{Cu}, \mathrm{ZnSOD}, \mathrm{MnSOD}$ cũng có trình tự axit amin mang tính bảo thủ cao từ vi khuẩn cho tới động vật. Tuy vậy, MnSOD lại không nhạy cảm với cyanide và không bị ức chế bởi $\mathrm{H}_{2} \mathrm{O}_{2}$, do đó có khả năng hoạt động ở những nơi có nồng độ các chất oxi hóa cao như ty thể (Hodgson \& Fridovich, 1975).

Trong các nhóm giáp xác sử dụng hemocyanin để vận chuyển oxi, đã có các báo cáo về một hiện tượng độc đáo xảy ra trên một số loài, đó là sự thay thế $\mathrm{Cu}, \mathrm{ZnSOD}$ bằng MnSOD trong tế bào chất. Giả thuyết của nhóm tác giả đề xuất cho rằng sự biến mất của $\mathrm{Cu}, \mathrm{ZnSOD}$ xảy ra vì cạnh tranh nguồn nguyên tử $\mathrm{Cu}$ với quá trình tổng hợp hemocyanin. Thay vào đó, enzyme MnSOD trong tế bào chất (cytMnSOD) được hình thành qua sự nhân đôi gen mã hóa MnSOD trong ty thể (mtMnSOD) và đã thay thế cho $\mathrm{Cu}, \mathrm{ZnSOD}$ ở tế bào chất (cytCu, ZnSOD) (Hodgson \& Fridovich, 1975; Brouwer et al. 2003; GómezAnduro et al., 2006). Sự khác biệt chủ yếu giữa 2 loại cytMnSOD và mtMnSOD là một đoạn trình tự định hướng ở đầu $\mathrm{N}$ khiến cytMnSOD thiếu đi cấu trúc đặc trưng để di chuyển được vào ty thể và do đó định khu lại ở tế bào chất, trong khi ở mtMnSOD, đoạn trình tự này bị cắt bỏ khỏi dạng tiền chất trước khi enzyme di chuyển vào định khu ở ty thể (Gómez-Anduro et al., 2006).

Với đối tượng tôm sú Penaeus monodon, các nghiên cứu về $\mathrm{SOD}$ của loài này mới chỉ dừng ở giải trình tự gen và cho thấy có 2 loại SOD trong tôm sú là mtMnSOD (GenBank: AGI99530.1) và cytMnSOD (GenBank: ANZ80590.1). Trình tự axit amin được suy ra từ trình tự gen cho thấy mtMnSOD có 220 gốc axit amin và KLPT xấp xỉ $24,1 \mathrm{kDa}$, cytMnSOD có 287 gốc axit amin và KLPT xấp xỉ $31,4 \mathrm{kDa}$. Tuy vậy, chưa có nghiên cứu nào khẳng định được số lượng các đồng dạng SOD trong $P$. monodon cũng như tách chiêt, tinh sạch hay nghiên cứu tính chất enzyme này.

Trong hệ miễn dịch của các loài tôm, quá trình thực bào sử dụng các dạng oxi phản ứng (reactive oxygen species-ROS) để tiêu diệt tác nhân xâm nhiễm có thể gây hại đến tế bào khỏe mạnh, do ROS có tác dụng phá hủy cấu trúc của các đại phân tử sinh học như protein, carbohydrate, lipid và nucleotide (Yao et al., 2004). SOD chuyển hóa gốc $\mathrm{O}_{2}{ }^{-}{ }^{-}$(sản phẩm đầu tiên và cũng là sản phẩm nhiều nhất của quá trình bùng nổ hô hấp trong đáp ứng miễn dịch ở tôm) thành oxi và $\mathrm{H}_{2} \mathrm{O}_{2}$. Kết hợp với các enzyme khác như catalase, peroxidase..., SOD xử lý các ROS dư thừa, khử độc cho tế bào sau đáp ứng miễn dịch. Hoạt động này có ý nghĩa thiết yếu đối với sự sống của tế bào (Yao et al., 2007). Chính vì vậy nghiên cứu về SOD gốp phần làm sáng tỏ các cơ chế đáp ứng miễn dịch ở tôm.

Mặc dầu đã có nhiều nghiên cứu khác nhau về SOD ở tôm, tuy vậy cho đến nay chưa có dẫn liệu nào được công bố về tinh 
sạch và tính chất của $S O D$ trên tôm sú. Đây là lý do để chúng tôi thực hiện công trình nghiên cứu này.

\section{VÂT LIỆU VÀ PHƯƠNG PHÁP NGHIÊN CÚU}

Vật liệu là tôm sú sống, được Viện Nghiên cứu Nuôi trồng Thủy sản I cung cấp với khối lượng đồng đều, từ $12-15 \mathrm{~g} / \mathrm{con}$.

Các thiết bị chính được sử dụng bao gồm cột sắc ký (GE Healthcare, USA), máy đo quang phổ UV/VIS DU-800 (Beckman Coulter, USA), hệ thống điện di đứng (Biorad, USA), dụng cụ Amicon Ultra-15 Centrifugal Filter Unit MWCO 10 kDa (Sigma-Aldrich, USA).

Các hóa chất sử dụng trong nghiên cứu bao gồm xanthine, xanthine oxidase, cytochrome $\mathrm{c}$, albumin huyết thanh bò được mua từ Sigma Aldrich (USA), các hóa chất còn lại đều được mua từ các hãng tin cậy (Sigma-Aldrich, Serva...) và đạt độ tinh khiêt phân tích.

\section{Chuẩn bị dịch chiết chứa SOD từ tôm sú}

Tôm sú sống được giải phẫu để thu tim và cơ. Mẫu được nghiền và đồng nhất trong đệm lạnh Tris- $\mathrm{HCl} 50 \mathrm{mM}, \mathrm{pH} 8$ chứa $\mathrm{NaCl} 50$ mM theo tỉ lệ $200 \mathrm{mg}$ mẫu/ml đệm. Dịch đồng nhất sau đó được ly tâm ở 10.000 vòng/phút trong 10 phút ở $4^{\circ} \mathrm{C}$ để thu dịch trong.

\section{Định lượng protein}

Nồng độ protein trong dịch chiết được định lượng theo phương pháp Bradford dựa trên nguyên lí về sự thay đổi bước sóng hấp thụ của thuốc thử Bradford sau khi tạo phức đặc hiệu với protein (Bradford, 1976), sử dụng albumin huyết thanh bò làm chất chuẩn.

\section{Xác định hoạt độ SOD}

Hoạt độ SOD được xác định theo phương pháp của McCord Fridovich (1969), trong đó xanthine oxidase $(\mathrm{XO})$ xúc tác phản ứng oxi hóa xanthine đồng thời tạo ra gốc superoxide. Khi phản ứng có mặt cytochrome $\mathrm{c}\left(\mathrm{Fe}^{3+}\right)$ thì hợp chất này bị khử bởi gốc superoxide thành sản phẩm có bước sóng hấp thụ tối ưu ở 550 $\mathrm{nm}$. Hoạt độ của enzyme $\mathrm{SOD}$ được đo bằng mức độ ức chế phản ứng khử cytochrome $\mathrm{c}$. Phản ứng được thực hiện ở $25^{\circ} \mathrm{C}$ trong đệm phosphate kali $50 \mathrm{mM}$, pH 7,8 chứa EDTA $0,1 \mathrm{mM}$. Hỗn hợp phản ứng gồm xanthine $0,05 \mathrm{mM}$, cytochrome c $0,01 \mathrm{mM}$ và lượng xanthine oxidase vừa đủ sao cho độ hấp thụ đo ở bước sóng $550 \mathrm{~nm}$ đạt $0,025 \pm 0,005$ đơn vị hấp thụ/phút. Một đơn vị hoạt độ (U) SOD là lượng enzyme ức chế $50 \%$ phản ứng khử cytochrome $\mathrm{c}$ (tương đương với mức độ làm giảm độ hấp thụ $0,0125 \pm 0,005$ đơn vị hấp thụ/phút).

Việc xác định ảnh hưởng của các ion kim loại $\mathrm{Cu}^{2+}, \mathrm{Mn}^{2+}, \mathrm{Ca}^{2+}$ và $\mathrm{Zn}^{2+}$ được thực hiện bằng cách bổ sung các muối tương ứng $\left(\mathrm{CuCl}_{2}, \mathrm{MnCl}_{2}, \mathrm{CaCl}_{2}, \mathrm{ZnCl}_{2}\right)$ vào chế phẩm SOD ở nồng độ cuối $5 \mathrm{mM}$ và ủ hỗn hợp trong 20 phút, sau đó đo hoạt độ SOD còn lại. Mức độ ảnh hưởng của các chất được đánh giá bằng việc so sánh giữa hoạt độ khi không có và có chất ảnh hưởng.

Các thí nghiệm được lặp lại 3 lần. Số liệu được xử lý thống kê trung bình bằng phần mềm Microsof Excel 2013.

\section{Xác định đồng dạng SOD}

Các dạng SOD được phát hiện bằng phương pháp điện di gel polyacrylamide không biến tính kết hợp ủ cơ chất đặc hiệu theo Beauchamp \& Fridovich (1971). Gel polyacrylamide không biến tính được chuẩn bị theo phương pháp của Laemmli (1970) nhưng đã loại bỏ SDS và chất khử (dithiothreitol hay $\beta$-mercaptoethanol) trong thành phần gel và đệm mẫu.

Gel sau khi điện di được ngâm trong dung dịch nitro blue tetrazolium chloride (NBT) $2,45 \mathrm{mM}$ trong 20 phút, được ủ tiếp với đệm phosphate kali $50 \mathrm{mM}$, pH 7,8 có chứa TEMED $0,028 \mathrm{M}$ và riboflavin $0,028 \mathrm{mM}$ trong 15 phút ở nhiệt độ phòng, sau đó được phơi sáng. Dưới tác dụng của ánh sáng, riboflavin sinh ra gốc superoxide, gốc này khử NBT thành formazan, làm toàn bộ bản gel có màu xanh tím. Tại những vùng có $\mathrm{SOD}$, nhờ hoạt tính của enzyme, phản ứng khử NBT bị ức chế tạo thành những vạch sáng màu.

$\mathrm{H}_{2} \mathrm{O}_{2}$ được thêm vào dung dịch riboflavin ở nồng độ cuối $5 \mathrm{mM}$ để phân biệt các loại SOD dựa trên tính chất bị ức chế bởi $\mathrm{H}_{2} \mathrm{O}_{2}$ hay 
không của các loại SOD (Brouwer et al., 1997; McCord \& Fridovich, 1969).

\section{Xác định độ tinh sạch của SOD}

Độ tinh sạch của chế phẩm SOD được kiểm tra bằng phương pháp điện di gel polyacrylamide có SDS (SDS-PAGE) theo phương pháp của Laemmli (1976), sử dụng thang chuẩn PageRuler Plus Prestained Protein Ladder 10-250 kDa (Thermo Fisher Scientific, USA).

Gel sau điện di được nhuộm trong dung dịch nhuộm Coomassie Brilliant Blue G-250 (CBB) $0,025 \%$, methanol $30 \%$, axit acetic $10 \%$ và tẩy màu bằng cùng dung dịch pha $\mathrm{CBB}$ cho đến khi các nền gel sáng và các băng protein hiện rõ.

Tách, tinh sạch SOD bằng sắc ký qua cột trao đổi ion DE-52 cellulose

Dịch chiết từ huyết tương tôm sú được tinh sạch qua cột trao đổi ion DE-52 cellulose $(3 \times 23 \mathrm{~cm})$ đã được cân bằng trong đệm Tris$\mathrm{HCl} 50 \mathrm{mM}, \mathrm{pH} 8$ chứa $\mathrm{NaCl} 50 \mathrm{mM}$. Các protein không gắn cột được rửa khỏi cột bằng cùng đệm trên và protein gắn cột được rửa chiết bằng gradient nồng độ $\mathrm{NaCl}$ từ $50-1.000$ $\mathrm{mM}$ pha trong cùng đệm trên. Tổng thể tích rửa chiết bằng 10 lần thể tích gel. Các phân đoạn rửa chiết được xác định nồng độ protein dựa trên độ hấp thụ ở bước sóng $280 \mathrm{~nm}\left(\mathrm{~A}_{280}\right)$ và được xác định hoạt tính $\mathrm{SOD}$ theo phương pháp của McCord và Fridovich (1969).

Những phân đoạn có hoạt tính SOD được gộp lại, cô đặc và chuyển sang đệm acetate natri $50 \mathrm{mM}$, pH 5 chứa $\mathrm{NaCl} 50 \mathrm{mM}$ bằng dụng cụ Amicon Ultra-15 Centrifugal Filter Unit MWCO $10 \mathrm{kDa}$ theo hướng dẫn của nhà sản xuất (Sigma Aldrich, USA).

Tách, tinh sạch SOD bằng sắc ký qua cột trao đổi ion Q-sepharose

Chế phẩm SOD thu được từ cột DE-52 cellulose sau cô đặc và đổi đệm được tiếp tục tinh sach qua cột trao đổi ion Q-Sepharose ở điều kiện $\mathrm{pH} 5$, đệm acetate natri $50 \mathrm{mM}$ chứa $\mathrm{NaCl} 50 \mathrm{mM}$. Các protein không gắn cột được rửa khỏi cột bằng cùng đệm trên, các protein gắn cột được rửa chiết bằng gradient nồng độ $\mathrm{NaCl}$ từ $50-600 \mathrm{mM}$ pha trong cùng đệm trên với tổng thể tích rửa chiết gấp 8 lần thể tích gel. Các phân đoạn rửa chiết được đo nồng độ protein qua giá trị $\mathrm{A}_{280}$ và đo hoạt độ $\mathrm{SOD}$, đồng thời đánh giá độ tinh sạch qua SDSPAGE. Các phân đoạn có hoạt tính SOD được gộp lại, cô đặc bằng dụng cụ Amicon Ultra-15 Centrifugal Filter Unit MWCO $10 \mathrm{kDa}$ và bảo quản ở (-) $20^{\circ} \mathrm{C}$ đến khi dùng cho các thí nghiệm tiếp theo.

\section{KẾT QUẢ VÀ THẢO LUẬN}

\section{Hoạt độ của SOD trong mô cơ và trong huyết tương tôm sú}

Kết quả xác định hoạt độ SOD của mô cơ và huyết tương tôm sú (hình 1) cho thấy hoạt độ SOD tổng số trong mô cơ là $1107 \pm 137,4$ U/con và trong huyết tương là $112,8 \pm 96$ U/con (hình $1 \mathrm{~A})$. Như vậy, hoạt độ tổng số của SOD trong mô cơ cao hơn trong huyết tương gấp 10 lần $(P<0,05)$.

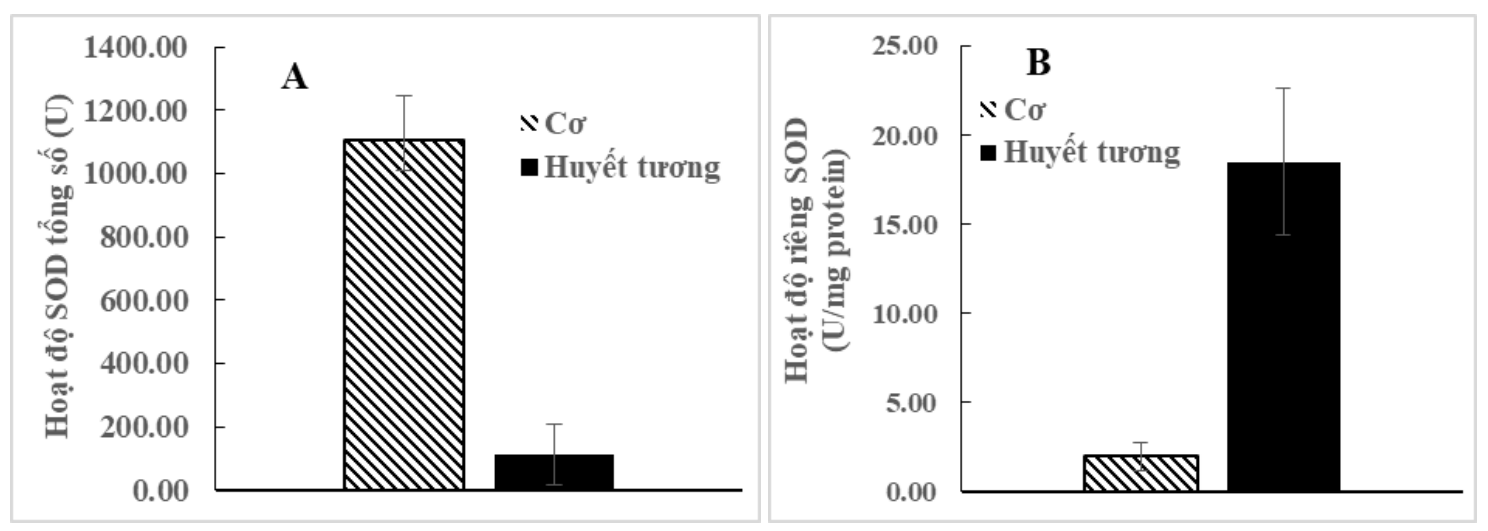

Hình 1. Hoạt độ tổng số $\mathrm{SOD}(\mathrm{A})$ và hoạt độ riêng $\mathrm{SOD}(\mathrm{B})$ của mô cơ và huyết tương tôm sú 
Trên cơ sở hàm lượng protein và hoạt độ SOD, hoạt độ riêng của SOD đã được tính ra, kết quả thu được cho thấy hoạt độ riêng SOD của mô cơ tôm sú là $2 \pm 0,8 \mathrm{U} / \mathrm{mg}$ protein và của huyết tương là $18,5 \pm 4,1 \mathrm{U} / \mathrm{mg}$ protein (hình 1B). Như vậy, hoạt độ riêng của SOD trong huyết tương cao hơn trong mô cơ gấp 9,2 lần $(P<0,05)$.

Có thể thấy, hoạt độ SOD tổng số của mô cơ tôm sú cao hơn trong huyết tương, điều này chủ yếu do lượng mô cơ lớn hơn nhiều so với lượng huyết thanh của một con tôm (cụ thể tỷ lệ khối lượng giữa mô cơ và huyết tương trong nghiên cứu này là 72,6 lần). Tuy vậy, hoạt độ riêng SOD của huyết tương cao hơn so với trong mô cơ, điều này chứng tỏ tỉ lệ $\mathrm{SOD} /$ protein tổng số của huyêt tương cao hơn so với trong mô cơ.

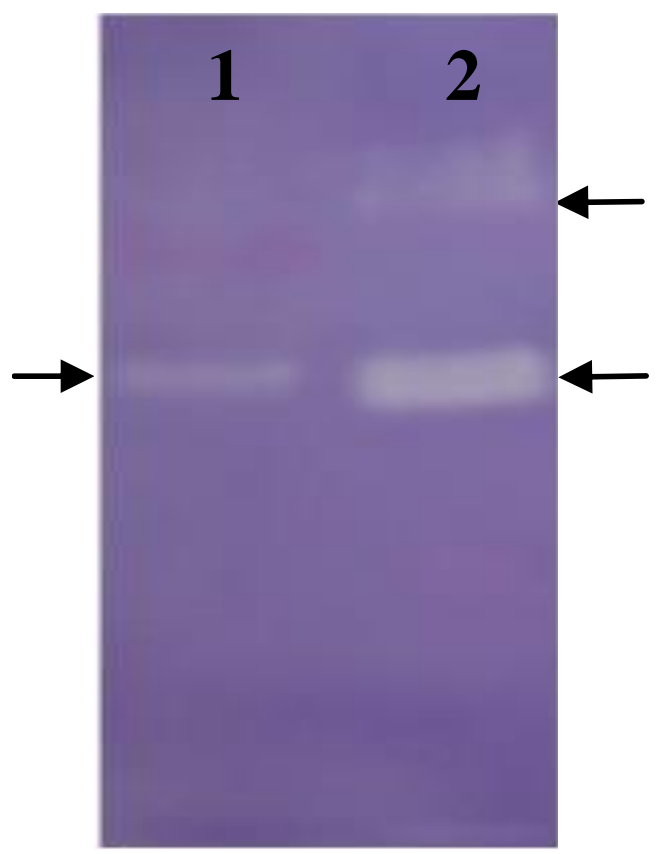

Hình 2. Điện di không biến tính phát hiện các dạng của SOD trong mô cơ và huyết tương tôm sú: 1: Dịch chiết mô cơ; 2: Dịch chiết huyết tương

Sử dụng phương pháp điện di trên gel polyacrylamide không biến tính và ủ trong cơ chất đặc hiệu đã cho phép phát hiện thấy có 2 dạng của $\mathrm{SOD}$, trong đó huyết tương có 2 dạng SOD và mô cơ chỉ có một loại $\mathrm{SOD}$ (hình 2), cả hai SOD này đều bị bất hoạt khi được xử lý nhiệt ở $100^{\circ} \mathrm{C}$ trong 15 phút, và kết quả thu được (dẫn liệu không nêu ở đây) cho thấy cả hai dạng $\mathrm{SOD}$ của tôm sú đều không bị bất hoạt bởi $\mathrm{H}_{2} \mathrm{O}_{2}$ (ở nồng độ 5 $\mathrm{mM}$ ), do đó chúng thuộc nhóm MnSOD. Kết quả phát hiện hai dạng SOD ở tôm sú trong nghiên cứu này là hoàn toàn trùng khớp với dữ liệu trên GenBank về hai trình tự gen mtMnSOD (AGI99530.1) và cytMnSOD (ANZ80590.1) của tôm sú.

Sự khác nhau về hoạt độ SOD cũng như phổ băng SOD giữa mô cơ và huyết tương tôm sú là những dẫn liệu đầu tiên được báo cáo trong nghiên cứu này. Việc phát hiện thấy hoạt độ riêng SOD của huyết tương tôm sú cao hơn trong mô cơ, kèm theo sự có mặt của cả hai dạng SOD trong huyết tương, trong khi trong mô cơ chỉ có một dạng SOD cũng là những dẫn liệu thú vị gợi ý về vai trò quan trọng của SOD ở trong huyết tương, nơi diễn ra các đáp ứng miễn dịch chủ yếu của tôm.

\section{Tách và tinh sạch SOD trong huyết tương tôm sú}

Sử dụng cột sắc ký trao đổi ion DE-52 cellulose ở điều kiện $\mathrm{pH} 8$, dịch chiết huyết tương tôm sú sau khi qua cột DE-52 cellulose cho 2 đỉnh hoạt tính SOD được rửa chiết ra ở nồng độ $\mathrm{NaCl}$ lần lượt là $400 \mathrm{mM}$ và $600 \mathrm{mM}$ (hình $3 \mathrm{~A}$ ). Đỉnh SOD thứ nhất (ký hiệu là SOD1) có hoạt độ tổng số là 1001,6 U và hoạt độ riêng $25,04 \mathrm{U} / \mathrm{mg}$ protein. Đỉnh SOD thứ hai (ký hiệu là SOD2) có hoạt độ tổng số là 930 U và hoạt độ riêng 80,19 U/mg protein.

Để tiếp tục tinh sạch SOD1, các phân đoạn qua cột DE-52 cellulose thuộc đỉnh SOD1 được gộp lại và tiếp tục cho tỉnh sạch qua cột trao đổi ion Q-Sepharose, sử dụng đệm acetate natri $50 \mathrm{mM}, \mathrm{pH}=5$ có chứa $\mathrm{NaCl} 50 \mathrm{mM}$. Kết quả thu được (hình 3B) cho thấy phần protein gắn cột được rửa chiết ra ở nồng độ $\mathrm{NaCl} 400 \mathrm{mM}$ dưới dạng một đỉnh lớn, đỉnh này có hoạt tính SOD. Chế phẩm SOD1 sau khi sắc ký qua 2 cột trao đổi ion có hoạt độ tổng số là 894,5 U và hoạt độ riêng là $357,8 \mathrm{U} / \mathrm{mg}$ protein. Như vậy qua bước này, độ sạch của chế phẩm đã tăng lên gấp 31,2 lần so với dịch chiết ban đầu (bảng 1). 

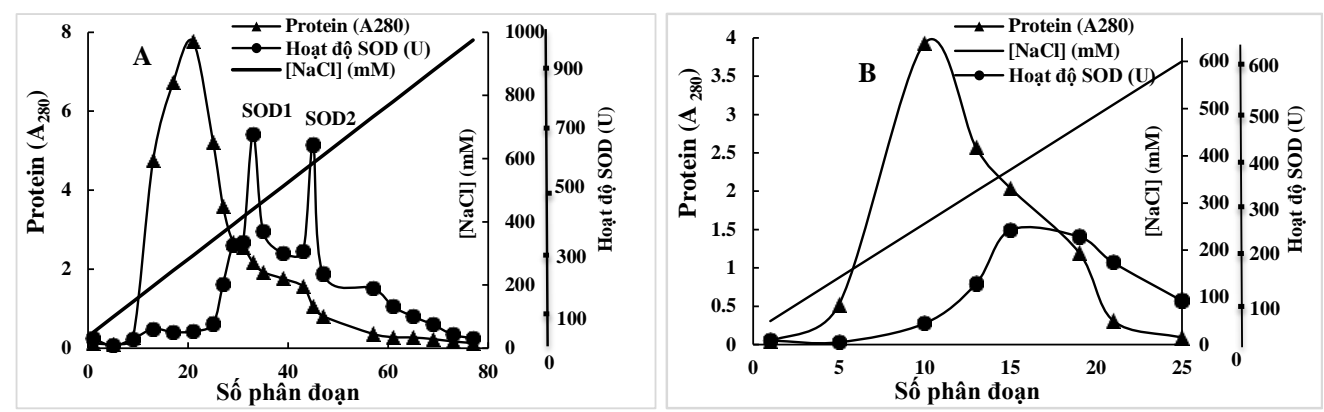

Hình 3. Sắc ký đồ của dịch chiết huyết tương tôm sú qua cột trao đổi ion $\mathrm{DE}-52$ cellulose $\mathrm{pH}=8(\mathrm{~A})$ và qua cột $\mathrm{Q}$-sepharose $\mathrm{pH}=5(\mathrm{~B})$

Bảng 1. Tóm tắt các bước tinh sạch SOD1 của tôm sú

\begin{tabular}{|l|c|c|c|c|}
\hline \multicolumn{1}{|c|}{ Các bước tinh sạch } & $\begin{array}{c}\text { Protein tổng số } \\
(\mathrm{mg})\end{array}$ & $\begin{array}{c}\text { Hoạt độ tổng số } \\
(\mathrm{U})\end{array}$ & $\begin{array}{c}\text { Hoạt độ riêng } \\
\text { (U/mg protein) }\end{array}$ & $\begin{array}{c}\text { Độ tinh sạch } \\
(\text { lần})\end{array}$ \\
\hline Dịch chiết huyết tương & 515,8 & 5911,1 & 11,5 & 1 \\
\hline DE-52 cellulose & 40,0 & 1001,6 & 25,0 & 2,2 \\
\hline Q-Sepharose & 2,5 & 894,5 & 357,8 & 31,2 \\
\hline
\end{tabular}

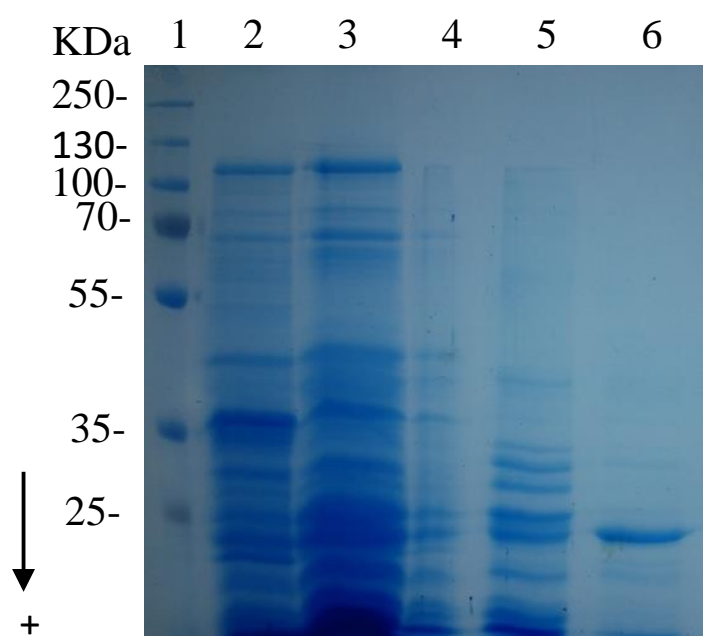

Hình 4. SDS-PAGE chế phẩm SOD1 của tôm sú

Ghi chú: 1: Thang chuẩn protein; 2: Dịch chiết huyết tương; 3: Chế phẩm SOD1 qua cột DE-52 celluose đã được cô đặc; 4: Phân đoạn không gắn cột Q-Sepharose; 5: Phân đoạn đỉnh protein rửa chiết cột Q-Sepharose; 6: Phân đoạn có hoạt tính SOD rửa chiết qua cột Q-Sepharose.

Kết quả phân tích SDS-PAGE chế phẩm SOD1 của tôm sú (hình 4) cho thấy chế phẩm SOD1 qua cột DE-52 celluose vẫn còn chứa nhiều băng protein khác nhau, tuy vậy chế phẩm SOD1 sau khi qua cột Q-Sepharose chỉ cho một băng protein chủ yếu có KLPT xấp xỉ $24 \mathrm{kDa}$ (đường chạy 6 ), chứng tỏ các bước sắc ký đã cho phép loại bỏ nhiều protein không mong muốn và chế phẩm SOD1 là khá tinh sạch. Kết quả này gợi ý SOD1 thu nhận được là mtMnSOD (GenBank: AGI99530.1) chứa 220 gốc axit amin tính theo dữ liệu về gen và có KLPT tính toán lý thuyết khoảng 24,1 kDa. Nhìn chung, các loại MnSOD tinh sạch từ các loài khác nhau thường tồn tại ở dạng homodimer hoặc homotetramer được cấu thành từ các đơn vị có KLPT giống nhau (Yao et al. 2004).

\section{Một số tính chất của SOD1}

Khi tiến hành xác định hoạt độ của SOD1 ở các nhiệt độ khác nhau, kết quả thu được cho thấy, SOD1 thể hiện hoạt động tốt ở khoảng $40-50^{\circ} \mathrm{C}$, và hoạt động tối thích ở $45^{\circ} \mathrm{C}$ (hình $\left.5 \mathrm{~A}\right)$. Kết quả xác định hoạt độ của SOD1 ở các pH khác nhau cho thấy SOD1 hoạt độ khác nhau không nhiều trong khoảng $\mathrm{pH}$ từ 5 đến 6 , tuy vậy enzyme hoạt động tôt nhất ở pH 5,5 (hình 5B).

Khi bổ sung vào hỗn hợp phản ứng các ion kim loại $\mathrm{Cu}^{2+}, \mathrm{Mn}^{2+}, \mathrm{Ca}^{2+}$ và $\mathrm{Zn}^{2+}$ dưới dạng các muối tương ứng $\left(\mathrm{CuCl}_{2}, \mathrm{MnCl}_{2}\right.$, $\mathrm{CaCl}_{2}, \mathrm{ZnCl}_{2}$ ) ở nồng độ $5 \mathrm{mM}$, kết quả xác định hoạt độ SOD còn lại (hình 6) cho thấy 
$\mathrm{Mn}^{2+}$ có khả năng hoạt hóa SOD1 lên đến $200 \%$. Kết quả này hoàn toàn đồng nhất với nhận định trên đây của chúng tôi cho rằng SOD1 thuộc vào nhóm $\mathrm{MnSOD}$. $\mathrm{Cu}^{2+} 5 \mathrm{mM}$ có khả năng ức chế hơn $50 \%$ hoạt độ SOD1, trong khi đó $\mathrm{Ca}^{2+}$ và $\mathrm{Zn}^{2+}$ ở nồng độ $5 \mathrm{mM}$ hoạt hóa nhe SOD1 (tăng khoảng 20\% hoạt độ). Tính chất này của SOD1 ở tôm sú khác với MnSOD tinh sạch từ mô cơ của tôm càng sông Macrobrachium nipponense (Yao et al. 2004), hay $\mathrm{Cu}, \mathrm{ZnSOD}$ được tinh sạch từ huyết tương của tôm càng sông $M$. nipponense (Yao et al., 2007), cụ thể hai SOD của $M$. nipponense đều bị ức chế bởi $\mathrm{Ca}^{2+}$ và $\mathrm{Zn}^{2+}$. Đây cũng là một sự khác biệt thú vị của SOD1 ở tôm sú cần được tiếp tục nghiên cứu.
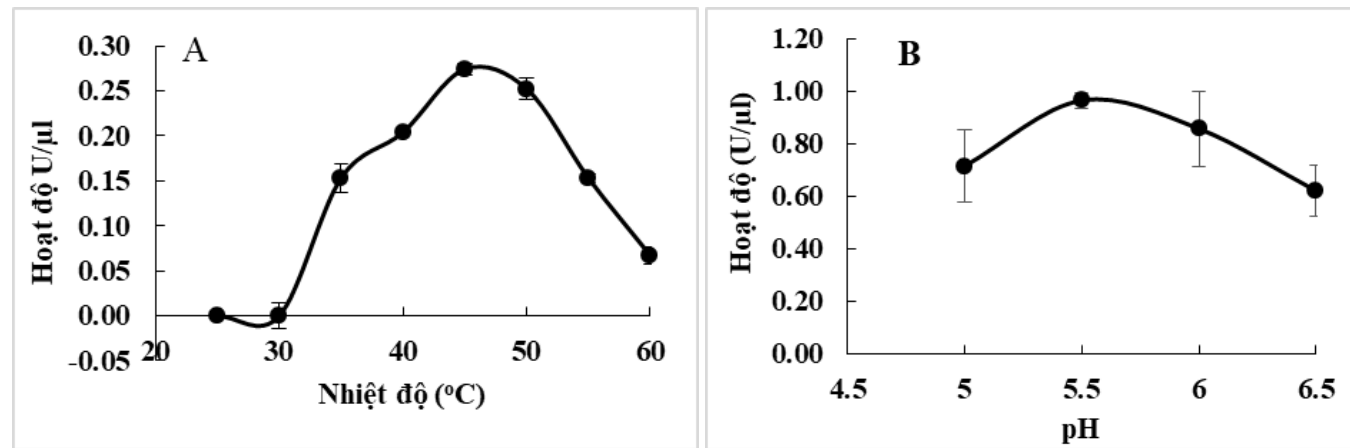

Hình 5. Ảnh hưởng của nhiệt độ (A) và pH (B) lên hoạt độ SOD1 của tôm sú

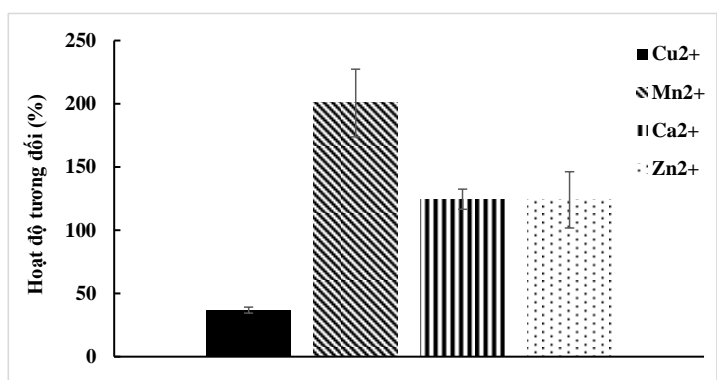

Hình 6. Ảnh hưởng của một số ion kim loại lên hoạt độ SOD1 tôm sú (Các kim loại $\mathrm{Cu}^{2+}$, $\mathrm{Mn}^{2+}, \mathrm{Ca}^{2+}, \mathrm{Zn}^{2+}$ tại nồng độ $5 \mathrm{mM}$ )

\section{KẾT LUẬN}

Đã xác định được hoạt độ SOD trong mô cơ và trong huyết tương của tôm sú và phát hiện thấy hoạt độ riêng của SOD trong huyết tương cao hơn trong mô cơ tới 9,2 lần. Có hai loại SOD ở trong tôm sú, trong đó trong huyết tương có hai loại và trong mô cơ có một loại, cả hai đều không bị ức chế bởi $\mathrm{H}_{2} \mathrm{O}_{2}$. Đã tinh sạch tới mức gần đồng nhất về điện di một SOD (SOD1) từ huyết tương tôm sú, SOD1 hoạt động tối thích ở $45^{\circ} \mathrm{C} ; \mathrm{pH} 5,5$; bị ức chế bởi $\mathrm{Cu}^{2+}$, được hoạt hóa mạnh bởi $\mathrm{Mn}^{2+}$ (tăng thêm $100 \%$ hoạt độ), và $\mathrm{Ca}^{2+}$ và $\mathrm{Zn}^{2+}$ hoạt hóa một phần (tăng khoảng 20\% hoạt độ). Đây là nghiên cứu đầu tiên về tinh sạch và nghiên cứu tính chất của $\mathrm{SOD} 1$ của tôm sú.

Lời cảm on: Công trình nghiên cứu được thực hiện với sự hỗ trợ kinh phí cho Nhóm Nghiên cứu mạnh Công nghệ Enzyme và Protein của Trường Đại học Khoa học Tự nhiên (năm 2019) và một phần kinh phí của đề tài NAFOSTED, mã số 106.02.2018.07.

\section{TÀI LIỆU THAM KHẢO}

Beauchamp C. and Fridovich I., 1971. Superoxide dismutase: improved assays and an assay applicable to acrylamide gels. Anal. Biochem., 44(1): 276-287.

Bradford M. M., 1976. A rapid and sensitive method for the quantitation of microgram quantities of protein utilizing the principle of protein-dye binding. Anal. Biochem., 72(1-2): 248-254.

Brouwer M., Brouwer T. H., Grater W., and Brown-Peterson N., 2003. Replacement of a cytosolic copper/zinc superoxide dismutase by a novel cytosolic manganese superoxide dismutase in crustaceans that use copper (haemocyanin) for oxygen transport. Biochem. J., 374(1): 219-228. 
Brouwer M., Brouwer T. H., Grater W., Enghild J. J., and Thogersen I. B., 1997. The paradigm that all oxygen-respiring eukaryotes have cytosolic CuZnsuperoxide dismutase and that $\mathrm{Mn}$ superoxide dismutase is localized to the mitochondria does not apply to a large group of marine arthropods. Biochemistry, 36(43): 13381-13388.

Fridovich I., 1975. Superoxide dismutases. Ann. Rev. Biochem., 44(1):147-159.

Gómez-Anduro G A., Barillas-Mury C. V., Peregrino-Uriarte A. B., Gupta L., Gollas-Galvan T., Hermandez-Lopes J., Yepiz-Plascencia G., 2006. The cytosolic manganese superoxide dismutase from the shrimp Litopenaeus vannamei: molecular cloning and expression. Develop. Comp. Immunol., 30(10): 893-900.

Hodgson E. K. and Fridovich I., 1975. Interaction of bovine erythrocyte superoxide dismutase with hydrogen peroxide. Inactivation of the enzyme., Biochemistry, 14(24): 5294-5299.
Laemmli U. K., 1970. Cleavage of structural proteins during the assembly of the head of bacteriophage T4. Nature, 227(4): 680-685.

McCord J. M. and Fridovich I., 1969. Superoxide dismutase an enzymic function for erythrocuprein (hemocuprein). J. Biol. Chem., 244(22): 6049-6055.

Yao C. L., Wang A. L., Wang W. N., and Sun R. Y., 2004. Purification and partial characterization of $\mathrm{Mn}$ superoxide dismutase from muscle tissue of the shrimp Macrobrachium nipponense. Aquaculture, 241(1-4): 621-631.

Yao C. L., Wang A. L., Wang Z. Y., Wang W. N., and Sun R. Y., 2007. Purification and partial characterization of $\mathrm{Cu}, \mathrm{Zn}$ superoxide dismutase from haemolymph of Oriental river prawn Macrobrachium nipponense. Aquaculture, 270(1): 559-565. 